\title{
Using an option pricing approach to evaluate strategic decisions in a rapidly changing climate: Black-Scholes and climate change
}

\author{
Matthew Sturm ${ }^{1}$ (D) Michael A. Goldstein ${ }^{2}$ • \\ Henry Huntington ${ }^{3}$ - Thomas A. Douglas ${ }^{4}$
}

Received: 25 May 2016 / Accepted: 16 November 2016/Published online: 25 November 2016

(C) The Author(s) 2016. This article is published with open access at Springerlink.com

\begin{abstract}
Nature provides critical ecosystem services on which society and businesses rely, but the effort and cost of utilizing those services can change with the climate. Both climatic trend and variance affect these efforts and costs, creating a complex decision space where uncertain future predictions are the rule. Here, we show how these problems mimic option payoffs and demonstrate a modified version of the Black-Scholes option pricing formula (widely used in finance) to analyze these types of business-climate decisions. We demonstrate the method by (1) examining the viability of building ice roads in the Northwest Territories of Canada, where a strong negative warming trend is underway, and (2) applying it to the problem of the ongoing California drought, estimating expected water costs with and without storage. The method is novel and provides a simple and accessible way to make such assessments to at least a first-order approximation. While our focus here is on business situations where decisions are usually based on money, we suggest that a similar approach could be used beyond the business world in examining risk and attributing that risk to climate variance vs. trend.
\end{abstract}

Electronic supplementary material The online version of this article (doi:10.1007/s10584-016-1860-5) contains supplementary material, which is available to authorized users.

Matthew Sturm

msturm1@alaska.edu

1 Geophysical Institute, University of Alaska-Fairbanks, Fairbanks, AK 99775, USA

2 Babson College, Babson Park, MA 02457, USA

3 Huntington Consulting, Eagle River, AK 99577, USA

4 U.S. Army Cold Regions Research and Engineering Lab-Alaska, Ft. Wainwright, AK 99703, USA 


\section{Introduction}

The Earth provides essential ecosystem services on which society and commerce depend (Costanza et al. 2014; Daily 1997). Sunlight and rainfall for lumber and crops are examples where these free services can be utilized with only a limited amount of infrastructure. Generating and transmitting hydroelectric power and large-scale irrigation projects are examples where harvesting nature's bounty requires more extensive infrastructure, such as dams, substations, and canals. In both cases, the natural systems that are the source of the no-cost services respond directly, sometimes dramatically, to changes in climate. Consequently, a changing climate affects not only when, where, and what services will be available but also the extent and cost of infrastructure and human effort that will be required in harvesting and utilizing those services.

Making wise decisions at the intersection of these two systems, one natural and one human, is at the heart of adaptation to climate change (Linnenluecke and Griffiths 2012; Tallis et al. 2008). That intersection space is complex and messy: it includes the coupled worlds of commerce and politics, as well as the physical, chemical, and biological intricacies of the natural world. In addition, climate predictions are usually not accurate or reliable enough for the purpose of informing specific, short-term decisions (Lempert et al. 2004), greatly increasing risk. Consequently, any method or tool that allows for a quantitative valuation of ecosystem services in a volatile and rapidly changing climate is potentially useful.

One way of approaching such decisions has been to create an ensemble of future climate states (Giorgi and Francisco 2000), downscale these (Tebaldi and Knutti 2007; Wilby and Dessai 2010), then apply a range of climate, business, perhaps hydrologic (Blöschl and Montanari 2010; Cervigni et al. 2015; Groves et al. 2013; Harding et al. 2012) and decision models (Herman et al. 2015) to the human-climate system of interest. Are there other, perhaps simpler, tools that can be used to examine this intersection of human and natural systems? Here, we note that many socio-climate problems mimic options and could be evaluated similarly. In addition to a general option valuation approach, we also offer here a useful tool in the form of a modified Black-Scholes (Black and Scholes 1973) option pricing formula (B-S formula), a well-known financial formula that prices stock options. Replacing stock price volatility with climatic variance, and running scenarios to mimic climatic trends, we have found that we can reconfigure the B-S formula in way that allows us to explore the linked behavior of these two climate parameters.

Option pricing uses return distributions to predict future costs in a system (stock options) that has a sharply asymmetric payoff, with zero payoff below a critical point and increasing profit once that threshold is surpassed. Inherent in the approach is the use of a binary payoff function $(\max [0, S-K]$ where $S$ is the current stock price and $K$ is the strike price); the same function describes ecosystem services where a change in climate can require a state change in the method of utilizing the service. We modify the inputs in the B-S formula to estimate the expected costs for these socio-climatic systems. For instance, a farmer who incurs no irrigation costs when rainfall exceeds the amount of water needed by his crops incurs increasing costs when rainfall falls below that threshold and he has to pump or purchase water. Our method of exploration, with the resulting analyses (mostly done graphically), clarify in unique ways the combined impact of climate trend and variance on business costs associated with ecosystem service use.

The estimates derived using a modified B-S formula closely match values from the general option valuation approach, indicating that the B-S results, which are easier to derive, can be 
used with confidence at least as a starting point in evaluating the cost of an anticipated impact or the merits of a particular decision. While the approach is similar in spirit to real options in that the underlying variable is not traded (Myers 1977; Trigeorgis 1993), a key difference is there is no choice on the part of the stakeholders or operators as to whether to exercise the "option." The B-S formula has been used in climate studies before (Tucker (1997); Fan (2006); and Gersonius et al. (2013)), but our application of the option approach is different.

In developing our method, we have purposely restricted our focus to business and specifically those sectors that rely directly on an ecosystem service. This restriction allows us to couch decision-making on the basis of money, though other factors often play a role. It also allows us to focus on a narrow temporal-spatial realm of climate (Fig. 1 after Clark 1985). The full realm spans 10 orders of time, while business decisions are made on temporal scales that run from less than a year to typically no more than 10 years, with 4 years being common (Table 1). The spatial scales of business, while harder to define, range from local $(\mathrm{km})$ to regional. Combined, these limits greatly reduce the overlap between business decisions and climate scales, allowing for considerable simplification. In simplest terms, businesses tend to focus on inter-annual variability (e.g., a parka manufacturer worries more whether next winter will be cold, not whether the climate is changing). What is notable is that the overlap does not include global warming trends, which require about 30 to 50 years to manifest. Given the potential existential threat posed by global warming trends, it is not surprising that these garner a lot of attention, but when it comes to business, climate variance drives the bulk of everyday decisions.

\section{Modeling a socio-climatic system using an option-like approach}

The B-S formula (Black and Scholes 1973; Chriss 1996) ${ }^{2}$, which is a special case of general option theory (Kallianpur and Karandikar 2012), was specifically developed to assist stock traders to decide whether a stock option was priced fairly (Fig. 2). The length of the option contract (e.g., 6 months) and the appropriate interest rate also determine the price. When a put option $^{3}$ contract is first initiated, uncertainty in the final stock price is at a maximum, the potential for a larger payoff is greater, and therefore the cost of the option higher. As the option expiration date approaches, the likelihood of large changes in stock price decreases, as does the option price. Upon expiration of the option, the system switches from probabilistic to deterministic: if the stock price is lower than the strike price, the holder of a put option may choose to exercise the option at the current stock price, and the payoff is the difference between the two. If the stock price is higher than the strike price, the option is not likely to be exercised and the payoff is zero. A key point is that upon expiration, predicted values become realized, with the option curve at expiry the realized cost curve. All other (pre-expiry) curves

\footnotetext{
${ }^{1}$ An example makes this distinction clearer: a real option for a mine owner might be to shutter a mine when commodity prices drop. However, if the owner decides to operate the mine, then fuel and supplies must be delivered at the mine regardless of transportation costs, and these may depend on climatic conditions. Our method allows computation of the transportation costs as a function of varying climate conditions. If, after those computations, the owner finds the expected cost too high, he may then exercise the real option of shutting the mine.

${ }^{2}$ Development of the B-S formula eventually led to a Nobel Prize for its originators, but not before the paper explaining the formula had been rejected by several journals.

${ }^{3}$ Put options pay off when the stock price drops below the strike price (i.e., the buyer of the option bets the stock will be worth less at a later date), while call options pay off when the stock price rises above the strike price.
} 
Fig. 1 Spatial-temporal scales of climate (after Clark 1985). We have superimposed the time and space scales of businesses (see Table 1) denoted by the dashed box. It does not overlap global warming trends

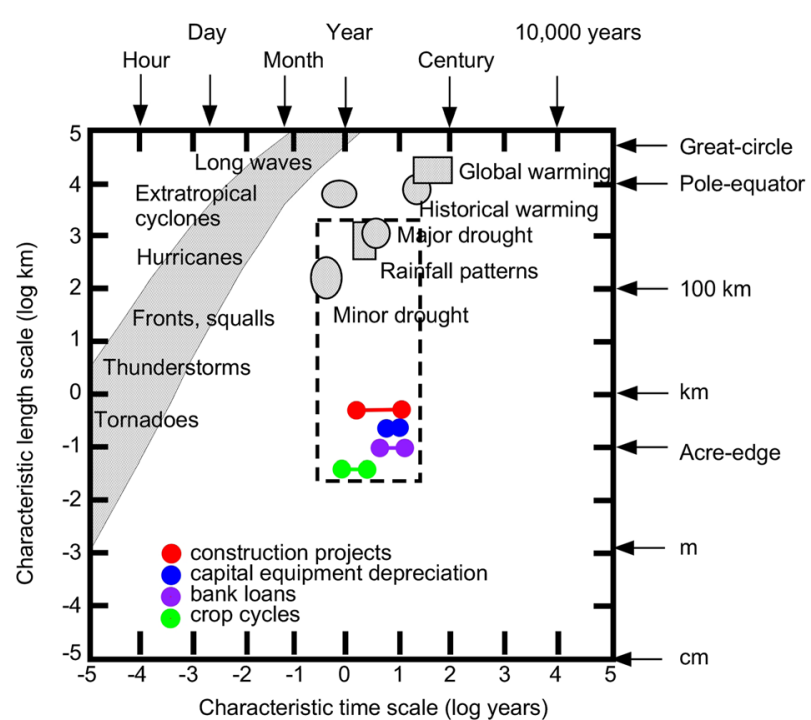

are probabilistic. This family of curves lies en échelon above the realized cost curve, with each higher curve a function of a longer period remaining to expiry and/or increasing stock price volatility (variance). While this is true for most options, the B-S formula provides a closedform solution (for certain distributions) that is easier to compute.

\section{Example I: ice roads and Black-Scholes}

It was while studying ice roads in the Northwest Territories (NT) of Canada that we first noticed the strong similarity between put option curves (Fig. 2) and the cost curves we were constructing to describe the operation of ice roads that supply diamond mines north of Yellowknife (Figs. 3 and 4). Nature provides a free ecosystem service (in the form of winter cold) for this road network in a region that is otherwise roadless. Once the roads are

Table 1 Typical business time scales

\begin{tabular}{ll}
\hline Type & Duration (years) \\
\hline Agriculture (crops) & 0.3 to 1 \\
Mines & 5 to 10 \\
Corporate debt & 1 to 10 \\
Capital budgets & 3 to 5 \\
Depreciation_cars ${ }^{\text {a }}$ & 3 to 6 \\
Depreciation_oil wells & 6 \\
Depreciation-ships $^{\mathrm{a}}$ & 6 \\
Depreciation-farm equipment $^{\mathrm{a}}$ & 18
\end{tabular}

IRS (2015) How to Depreciate Property. Internal Revenue Service (ed.). U.S. Government, Washington, DC, Pub. 946, p. 115

${ }^{a}$ From IRS (2015) 
Fig. 2 A typical put option graph (black labels) showing the strike price $(K)$ and the payoff (y-axis), which increases linearly as the stock price $(S)$ falls. Option pricing computed using a general option formula are shown for 1 year (red) and 6 months (green) prior to expiry of the option. Longer times to expiry mean greater uncertainty due to volatility, hence higher potential payoffs. The analogous socio-climatic system is suggested by the blue labels

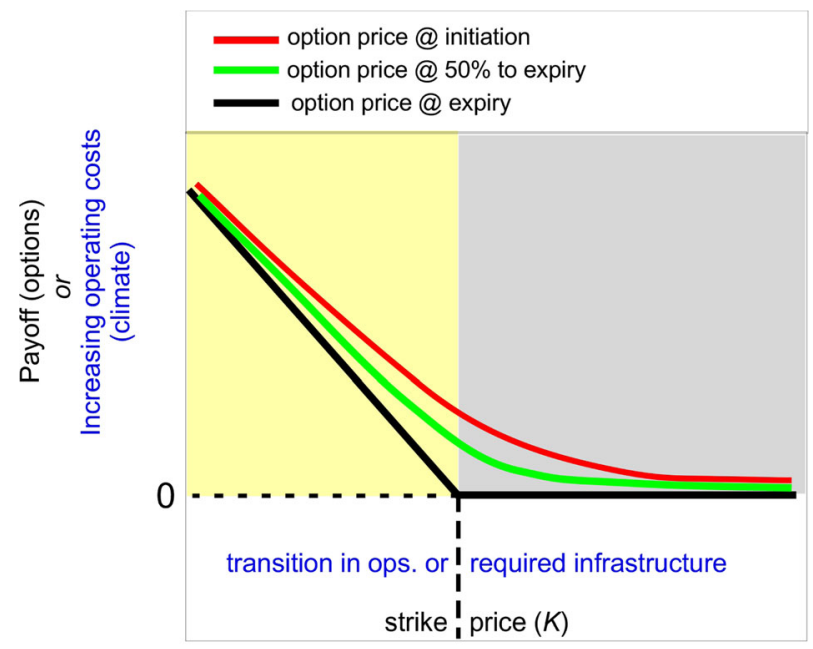

Stock Price (S) or Climate Metric

constructed, truck transport using the roads is a fraction of the cost of air cargo, the only other way of moving material to these highly profitable but remote mines. If the winter is cold enough, sufficient ice thickness can be produced so that the ice roads will last until all required cargo has been delivered to the mines. In a mild winter, the ice roads have failed early (Fig. 3), forcing the remaining cargo to be delivered by air at a steep premium. There has been a significant reduction in winter cold during the past 40 years (Fig. 3), suggesting (Stephenson et al. 2011) that ice roads might soon cease to be viable. Is this true?

To answer the question, we mapped the ice road system to a general option formula as well as to the B-S formula (Fig. 4). First, we replaced the strike price $(K)$ with the minimum season length sufficient to bring up the all the material needed by the mines by truck. This open season length is controlled by winter cold (Fig. 3), but that is only half the story (Supplement 1). Human effort, in the form of plowing snow, can enhance ice growth and increase the length of time the road stays open, while the number of trucks and the efficiency with which they are

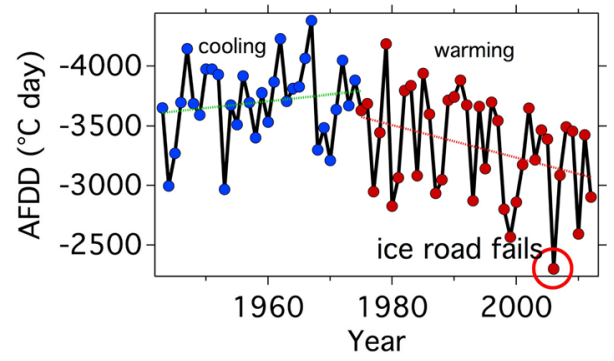

Fig. 3 Accumulative freezing degree days (AFDD) for Yellowknife, 1943-2012. In the B-S formula volatility is replaced by climatic variance, in this case AFDD. Winter cold (which freezes and thickens ice) is well represented by AFDD, from which the length of time the ice road stays open can be computed. AFDD has been on a downward trend since 1976, during which the variance of the time series has also increased (Levene Test $=6.2$ at a $98 \%$ confidence level). The one failure to date (2006: circled in red), which cost the mine operators millions of dollars in airfreight costs, was driven by both increasing variance and downward trend 


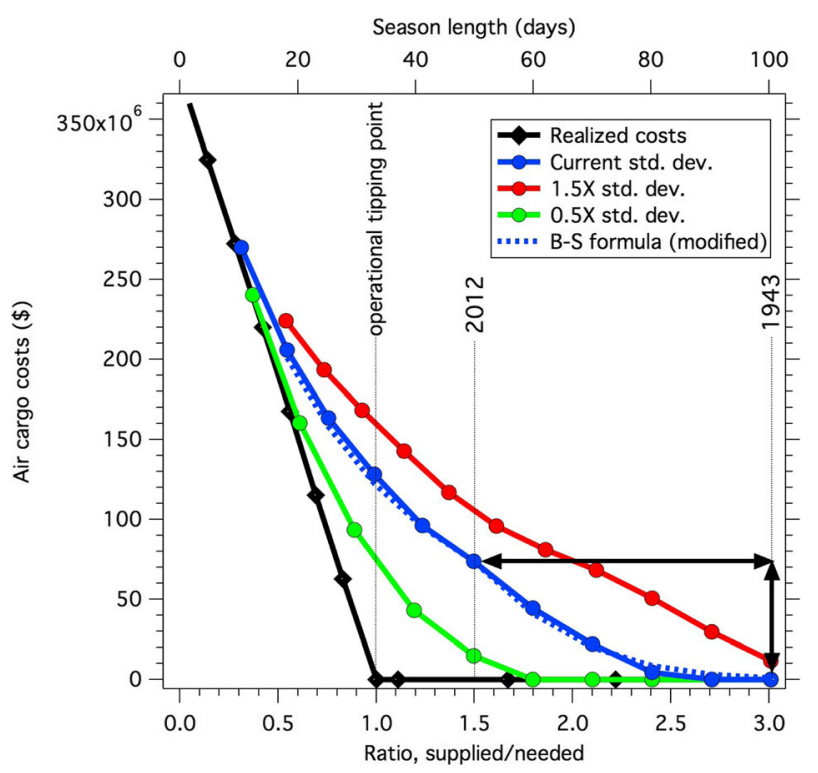

Fig. 4 Realized (black) and expected (blue, green, and red) cost curves for the ice road system. Here, the costs are those that would be incurred above and beyond construction and operation expenses. The average operational need is 180,000 tonnes delivered to the mines, which requires the road to be open 33 days, or a supply-to-need ratio of 1 (the OPT). The solid blue line is the expected cost curve for the current climate variance computed using a statistical transformation method; the dashed blue line was computed using the modified B-S formula (Supplements 1 and 2). Between 1943 and 2012, the average ice road-open season dropped by 50 days while the variance increased, raising the expected cost by $\$ 74$ million (black arrows). With an increase in variance of $1.5 \times$ (assumed for purposes of illustration), that figure rises to $\$ 109$ million (the jump from blue to red cost curves along the 2012 season length vertical dotted line)

used can reduce the length of time needed to transport all cargo. Consequently, the strike price is actually a function of an ecosystem service (cold) and human effort (plows and trucks). But unlike the supply of cold, the human component is not free. It comes at a cost of C\$18.6 million each year in construction and operation costs. Composite (human plus nature) strike prices seem to be the norm for socio-climatic systems.

Next, we replaced payoff ( $P_{T}$, the y-axis in Fig. 2$)$ with an equivalent fiscal metric, in this case the marginal cost of flying cargo to the mines. In the case of the diamond mines, this is the marginal cost of air over truck transport, or \$2096/tonne, which when multiplied by the number of tonnes that need to be flown, produces the values on the y-axis in Fig. 4, which shows values from the general option approach in blue, green, and red.

To employ the B-S formula, we replace stock price volatility with the variance of the relevant socio-climatic metric (e.g., Fig. 3). When the distribution of this variance (or alternately, the standard deviation) is log-normal, it can be used directly in the B-S formula, which assumes an underlying log-normal distribution. But for the diamond mines it was not, so we had to employ an adjusted value (Supplement 2). We have found that this approach works with reasonable accuracy even for distributions that differ considerably from lognormality. The relevant metric was an adjusted value of the variance of the open season length. This metric does not appear explicitly in the graphical results but rather produces a family of curves in which higher variance results in a curves delineating increasingly higher expected costs. These expected costs represent a "best guess" of the potential costs that will be 
incurred before the actual climate conditions can be known and they form the basis of most business decisions, which invariably need to be made before the actual conditions (climate or business) have materialized. In mathematical terms, this mapping corresponds directly to a general option valuation formula:

$$
P_{T}=\int_{0}^{\infty} \max [0,(K-S)] p(S) d s=\int_{0}^{K}(K-S) p(S) d s
$$

where $K$ is the current value of the socio-economic metric and $p(S)$ is the distribution of that metric (typically represented by the variance or standard deviation).

In socio-climatic systems, the strike price corresponds to the operational tipping point (OPT), a point where an abrupt increase (or decrease) in the cost and/or work effort of utilizing the ecosystem service occurs. The OPT is largely determined by human needs, and in many cases (based on past operations) is well known for short periods, though over a period of a few decades the value is likely to change. More problematic is developing a quantitative climate time series that captures past, or future, climate conditions, and this is difficult whether using our method or GCMs. Nevertheless, we think the OPT is an extremely useful concept when considering responses to climate change across a wide range of businesses. Defining it forces one to think clearly about the ecosystem service that is being utilized, how climate moderates that service, and what labor and costs we incur in harvesting the service. Mathematically, we express OPT as the ratio between what nature is able to supply to what is needed, so the tipping point occurs at a value of 1 . In the case of the NT ice roads, this corresponds to being open for 33 days, which requires (in general) that nature deliver an ice thickness of $85 \mathrm{~cm}$ or more (Supplement 1).

Two fundamental climate-affected decisions face the owner/operators of the mine: (1) What is the financial risk of an ice road failure in the current climate, and (2) what would the risk be in a climate that is warmer (colder) and/or more (less) variable? The owner/operators must decide in late summer whether to commit to building ice roads the following winter, long before even a seasonal weather forecast is available. For many reasons (letting of construction and trucking contracts; hiring of road workers and drivers, obtaining permits, etc.), they cannot reduce their time to expiry: in other words, they are effectively always a half year out in the sense that they must assume maximum variance. What the operators do know (based on weather records) is the historical trend and variability of the winter weather and cold (Fig. 3), which is exactly analogous to the stock trader who knows the historic trend and volatility of a stock. ${ }^{4}$ Implicit is the assumption of some type of climate stationarity: that the past climate record is related in some functional way to future climate behavior. Mapped into the option formulation, perhaps across a range of climate scenarios, the resulting calculations and graphs allow the owners to address their questions and decide if an ice road is a viable solution.

The results are surprising and non-intuitive. First, even in the pre-climate warming world of 1971 (before the diamond mines were discovered in the 1990s), the expected flight costs of an imaginary ice road system would have been non-zero ( $\$ 4.4$ million). By 2012, after years of warming, with the diamond mines in place for 14 years, the expected costs had risen to $\$ 74$ million, yet the road-open season length had not dropped below the OPT: the decision to build the road had merely gotten riskier. This risk is real: in 2006, the ice road system failed

\footnotetext{
${ }^{4}$ Stock traders now use sophisticated techniques to estimate future prices; similarly, forecasts of future winter variance could be used, but for simplicity, and because long-range weather forecasting of variance is still in its infancy, we model future variation based on historical data.
} 
prematurely, resulting in what we estimate to be millions of dollars in air cargo costs. Should the warming trend continue as before, the mean road-open season length will drop below the OPT in 2031, but it is a mistake to assume ice roads would no longer be built after that point is passed. As long as the ice road system manages to allow enough transport by truck that the differential in the cost of the amount of cargo delivered over the road vs. by air exceeds the construction and operation costs of the road itself, ice road use will remain financially advantageous, just risky.

Figure 4 also clarifies the impact climatic variance has on the financial risk, and it is as large, if not larger, than the impact of climate trend. For example, were the variance to drop to half of current value, the change would reduce the expected cost to $\$ 22$ million, a reduction by a factor of 3. Conversely, increasing the variance by $50 \%$ would push the expected costs well past values that would otherwise not be realized for another 20 years of warming, to over $\$ 100$ million.

As cited above, alternative ways of achieving the same insights gave been developed. For instance, conducting a series of ensemble or multi-model runs of global circulation or regional climate models, then down-scaling these and integrating them with run-off or business models (or both) also allows for examination of the impact of both climate trend and variance on costs and outcomes and can be applied in more sophisticated ways (e.g. (Cervigni et al. 2015)) but these alternatives are typically more expensive and require greater computing tools and resources to implement. In contrast, option pricing, and particularly the use of the modified B-S formulation, can be performed using a simple spreadsheet. Once parameterized, the effect of changes in the variance or mean of the climate metric can be calculated in seconds.

One additional concept needs introducing and some explanation before we present additional examples. The concept is that of hedging through storage, a concept that has been known for thousands of years (see the Bible, Genesis 41). Unfortunately, in the case of ice roads, hedging through storage is not practical. The main cargo transported up the roads is fuel, and storage capacity at the mines is sufficient for only 1 year's operation. Expanding storage is too expensive without greater certainty in the lifespan of the mines. This is one reason why the system has an asymmetrical cost structure: excess costs in warm years cannot be offset by stockpiling in cold years. While systems that can be fully hedged through storage or financial markets would not typically have an asymmetric payoff profile, it turns out that many business systems that rely on nature's bounty in some way (see Supplement 2) are asymmetrical.

\section{Example II: California's water supply: more storage?}

In this second example, we apply our method to estimate additional water costs in a variable and changing climate. Our particular focus is the system of rivers, dams, and reservoirs that sustain millions of people living in California, as well as a multi-billion dollar agro-business. The majority of the water in this system comes from the Sierra Nevada snow pack (California 2016; Messerli et al. 2004), which accumulates through the winter and then melts slowly in spring and summer, a natural storage facility (Messerli et al. 2004). The system is in a decadelong drought (Diffenbaugh et al. 2015; University of California 2016), primarily due to record low snowfall, that has caused agricultural losses exceeding \$2.7 billion (Howitt et al. 2014, 2015). The ecosystem service is run-off and it can be measured directly, though the 
underlying climate metrics are winter precipitation and spring/summer heating, the latter controlling the rate of melt (Hanak et al. 2011).

The Merced River is a good representative of the larger water system. It arises in Yosemite Valley and supplies water to the Merced Irrigation District. ${ }^{5}$ The mean annual run-off above all impoundments over the past 98 years has been 557 million cubic meters per year (cmy) and has shown little trend, but year-to-year variability is almost half of the mean (249 cmy) (Fig. 4). We use the detrended time series (mean of 600; standard deviation of $248 \mathrm{cmy}$ ) and assume the irrigation district needs a bit more water than the river supplies on average: 650 million cmy (the $O P T$ ), and that when there is a shortfall, groundwater will be purchased at $\$ 0.73 \mathrm{~m}^{-3}$ (Somer 2014). Trans-district water purchasing has been widespread during the drought, though in reality, if the purchase price of water was to increase too much, farmers have the option of letting their land go fallow.

Mapping this system into an option framework, we examine first the hypothetical case in which there is no storage (i.e., no reservoirs) ${ }^{6}$, after which we examine the effect of partial storage and examine the difference. We again define the strike price (or OPT) as the ratio of the cumulative annual discharge to the amount of water needed by the irrigation district. At ratios less than 1.0, water must be purchased. Expected water costs for an undammed river (Fig. 5, black line with circles) and an OPT of 0.92 (\$600 million/\$650 million) are over $\$ 95$ million (Fig. 6). As before, lateral movement (left or right) on the graph corresponds with the impact of trend on the expected cost, while changes in variance move the cost up or down, jumping from one cost curve to another. A 50\% reduction in standard deviation (easily achieved by building a dam) reduces the expected water costs to $\$ 59$ million, so it is easy to see why this river was dammed as early as 1926 (Old Exchequer Dam).

We now model the system with storage. The New Exchequer Dam on the Merced River opened in 1967. The dam holds up to 1.27 billion cubic meters of water, but since it is difficult to pump water when the reservoir level drops too low, we assume the useable volume is about 1 billion cubic meters. Once half full, we assume that only 100 million cubic meters of water can be added per year due to requirements for maintaining adequate capacity for flood mitigation. Including the effect of the reservoir storage and these filling rules, we created an altered time series (Fig. 5, red line and pink filled area), then from this we recalculated the expected costs (Fig. 6). Not surprisingly, the existence of storage substantially changes the discharge time series (Fig. 5), the variance, and produces a dramatic reduction in the expected costs for water purchase. The variance drops from 248 to 146 million cubic meters, which reduces the expected costs by $\$ 46$ million ( $\$ 95-\$ 49$ million). For the more than 40 other water reservoirs in California (Reservoirs 2016), the same order of valuations would likely be true, conservatively suggesting an overall annual monetary value of water storage to the State of California of at least $\$ 2$ billion ${ }^{7}$.

For illustration purposes above, we assumed a supply-to-need ratio slightly less than one, and in reality, this is often the case. Need often overtakes supply. For example, within 30 years of the original dam being built on the Merced River (1926), agricultural demand for water had

\footnotetext{
${ }^{5}$ This district, like most of California, is also in a severe drought: http://www.co.merced.ca.us/index. aspx?NID=2038

6 The Merced River currently has three dams, the New Exchequer Dam (which replaced the original Exchequer Dam in 1967), which impounds Lake McClure, and the McSwain and Crocker-Huffman dams, which impound much smaller lakes.

${ }^{7}$ There are well over 100 reservoirs in California. The largest 43 hold $41 \mathrm{~km}^{3}$ of water with Lake McClure representing $3 \%$ of the total of the top 43 .
} 


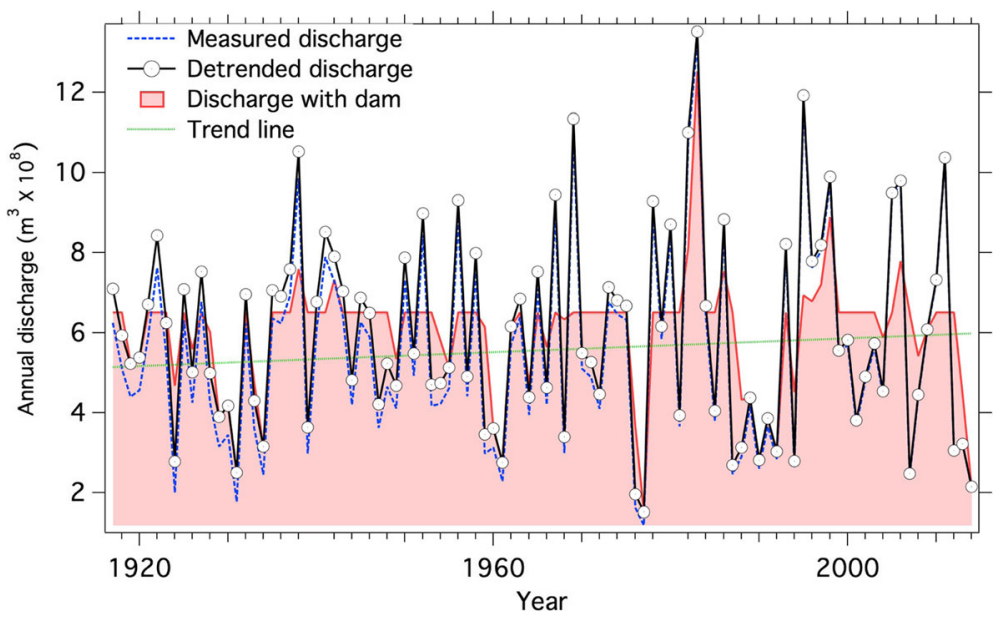

Fig. 5 The measured cumulative annual discharge of the Merced River above all impoundments (blue dashed line:(USGS 2014)). The discharge record has a small (15\%) increasing trend (green line) that has been removed to produce a detrended time series (black line with circles). The red line with pink fill represents the estimated discharge downstream of the New Exchequer Dam, which in most years can supply the needed 650 cmy. Flood mitigation regulations require that once the reservoir reaches $50 \%$ full, water can no longer be impounded, so in exceptionally wet years (e.g., 1983) the discharge exceeds 650 million cmy. The discharge drops below 650 million cmy when the reservoir is so low that water can no longer be withdrawn for irrigation

grown to the point where the dam capacity was no longer enough, and the farmers (successfully) advocated for a bigger dam (Hanak et al. 2011).

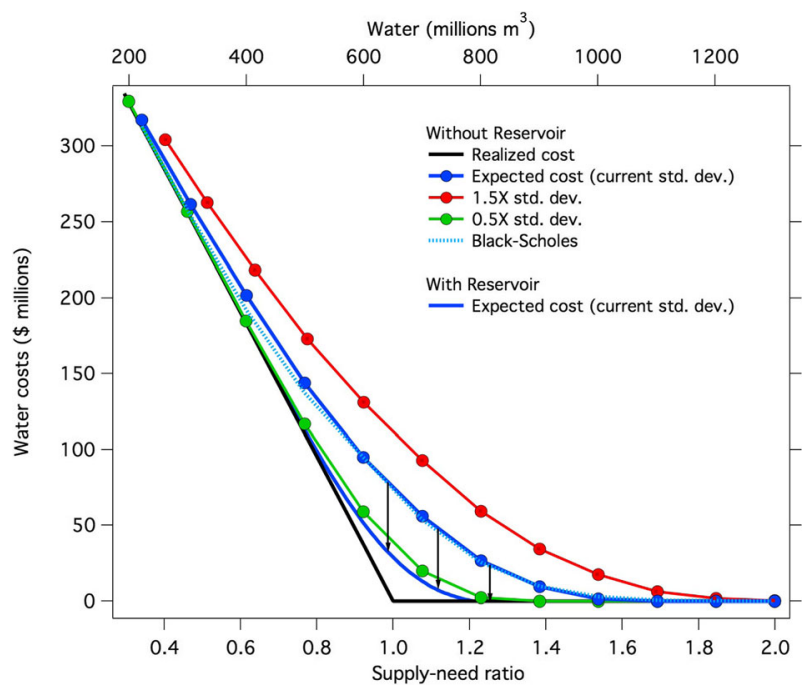

Fig. 6 Realized (black) and expected (blue, green and red) water costs for the Merced River assuming no reservoir. The average operational need (threshold) is assumed to be 650 million cubic meters of water, equivalent to a supply-to-need ratio of 0.92 , which in 2014 implies an expected cost of $\$ 95$ million if there was no dam. With the New Exchequer Dam in place, the expected cost curve shifts downward (indicated by the black arrows) by over $\$ 46$ million (lower blue line). The results were computed using both a statistical transformation method and the modified B-S formula (Supplement 2), and are nearly identical 


\section{Harnessing and expanding the power of the option-like approach}

The basic requirements for harnessing the power of the option-like approach are (1) recognizing that there is an asymmetrical structure in the socio-climatic system, (2) identifying the operational threshold (OPT), (3) understanding and correctly parameterizing the climate metric that affects operations, and (4) finding or developing a climatic time series of sufficient length to obtain the variance.

In the two examples above, we had sufficient data to delineate $p(S)$ and could therefore apply the generalized method, as well as the modified B-S formula, to compute expected costs (Supplement 2), but this is not always the case. Fortunately, the B-S formula is not only fast and easy to use but does not require a long climate time series. For example, in the generalized method, a measured (or simulated) series as long as 50 years in length may be needed, and it may still underestimate the full probability space and variance because it lacks the more extreme excursions. This can lead to an underestimation of expected costs. By using the B-S formula, we are able to evaluate costs as if we had an infinite number of observations, reducing the problem of cost underestimation. Based on the examples we have investigated, means and variances computed from a few decades of data may be sufficient. Even if these values are not well established, they can be varied across a range to explore the set of likely outcomes. In the advent of having only a very limited data record, using the B-S formula is the easier and more efficient method.

Three additional socio-climatic business systems suggest where the method might be applied (see also the table in Supplement 3):

Agricultural insurance in Kenya Small-scale farmers in Kenya have long borne the risk of adverse weather, but there is a program (Osgood et al. 2007) that allows them to purchase crop insurance. In this program, payouts are made automatically if rainfall is below a threshold level during the growing season. Similar insurance is available for larger scale farming in the US and other places around the globe. For these programs to remain viable, premiums need to affordable yet still pay for the cost of the program. Climate trends, if present, can bedevil such a program. Over time, if the trend is to drier weather, the program will become more expensive for the insurer, while if the trend is to wetter weather, the farmers may have less incentive to purchase insurance unless the price drops. As noted by Tucker (1997), these "insurance policies are very much like put options" and the methods described here could be used to assess what the fair price of insurance might be in particular setting or to explore "what ifs" for future rainfall trends and variance.

Ice roads vs. barges in Alaska's north slope oil patch The Prudhoe Bay area of Alaska's north slope is home to many smaller oil fields. Some, like Point Thomson, are beyond the limits of the all-season road network, so they are accessed in winter by an ice road constructed by spraying water on tundra (in contrast to the frozen lakes in NT) and in summer by tug and barge when sea ice is gone. Freezing weather and sea ice conditions affect the viability and duration of both modes of transport. Assuming that the barge costs and ice road costs are not the same, the B-S formula method could be used to explore at what point barge transport should be used vs. tundra ice roads.

Shipping through the northern sea route The Northern Sea Route (NSR) connects the Pacific and the Atlantic by way of the Arctic Ocean to the north of Russia. In recent years, 
commercial interest in using this route has risen. A major challenge, however, is uncertainty surrounding the opening date for ship transits (i.e., when sea ice concentrations drop below a certain percentage) as well as the length of the shipping season (how long sea ice concentrations remain low). The viability of the NSR could be enhanced by constructing icestrengthened cargo ships. Option pricing could be used to calculate the expected costs of using the NSR vs. alternative routes such as the Suez Canal and also the merits of investing in ice-strengthened vessels as a form of hedging.

In conclusion, we believe there is a large range of problems for which the method we describe can provide actionable information. Researchers analyzing socio-climatic systems with a threshold and an asymmetric payoff structure will find that mimicking these systems using a general option valuation approach or the B-S formula provides useful insights into the impact of trend vs. variance. The use of the B-S formula in particular allows for relatively quick estimates (within minutes) of how expected costs would change for various changes in either the underlying climate or the underlying business or socio-political need. Perhaps most importantly, there is vast literature on applications of option valuation and the B-S formula in finance that could help advance climate analyses related to ecosystem services.

Acknowledgements The project was funded by the National Science Foundation (NSF-OPP- 0902130). We received substantial assistance from the Tibbitt-to-Contwyto Winter Road Joint Venture and from the Northwest Territories Department of Transportation. W. Oechel, T. Chapin, J. Walsh, and U. Bhatt made useful comments on older versions of the manuscript. Six Babson students, J. Chartier, P. Chung, G. Collins, N. Dagesse, N. Pineda, and J. Szeto assisted in ice road data collection.

Authors' contributions MS and MAG contributed equally in developing and creating the intellectual underpinnings of the paper, including developing and linking the physical and economic models and in writing the manuscript. HPH and TAD contributed to the project design, field work, discussions of key ideas, and manuscript preparation. All authors participated in writing the paper.

Open Access This article is distributed under the terms of the Creative Commons Attribution 4.0 International License (http://creativecommons.org/licenses/by/4.0/), which permits unrestricted use, distribution, and reproduction in any medium, provided you give appropriate credit to the original author(s) and the source, provide a link to the Creative Commons license, and indicate if changes were made.

\section{References}

Black F, Scholes M (1973) The pricing of options and corporate liabilities. J Polit Econ 637-654

Blöschl G, Montanari A (2010) Climate change impacts - throwing the dice? Hydrol Process 24:374-381

California (2016) Sierra Nevada Conservancy

Cervigni R, Liden R, Neumann JE, Strzepek KM (2015) Enhancing the climate resilience of Africa's infrastructure: the power and water sectors. World Bank Publications

Chriss N (1996) Black Scholes and beyond: option pricing models. McGraw-Hill

Clark WC (1985) Scales of climate impacts. Clim Chang 7:5-27

Costanza R, de Groot R, Sutton P, van der Ploeg S, Anderson SJ, Kubiszewski I, Farber S, Turner RK (2014) Changes in the global value of ecosystem services. Glob Environ Chang 26:152-158

Daily G (1997) Nature's services: societal dependence on natural ecosystems. Island Press

Diffenbaugh NS, Swain DL, Touma D (2015) Anthropogenic warming has increased drought risk in California. Proc Natl Acad Sci 112:3931-3936

Fan H (2006) The potential use of the Black-Scholes model in urban drainage risk management, MSc Thesis, Department of Civil and Environmental Engineering, Imperial College of Science, Technology and Medicine

Gersonius B, Ashley R, Pathirana A, Zevenbergen C (2013) Climate change uncertainty: building flexibility into water and flood risk infrastructure. Clim Chang 116:411-423 
Giorgi F, Francisco R (2000) Uncertainties in regional climate change prediction: a regional analysis of ensemble simulations with the HADCM2 coupled AOGCM. Clim Dyn 16:169-182

Groves DG, Fischbach JR, Bloom E, Knopman D, Keefe R (2013) Adapting to a changing Colorado River. RAND corporation

Hanak E, Lund J, Dinar A, Gray B, Howitt R, Mount J, Moyle P, Thompson B (2011) Managing California's water: from conflict to reconciliation. Public Policy Instit. of California

Harding B, Wood A, Prairie J (2012) The implications of climate change scenario selection for future streamflow projection in the Upper Colorado River Basin. Hydrol Earth Syst Sci 16:3989-4007

Herman JD, Reed PM, Zeff HB, Characklis GW (2015) How should robustness be defined for water systems planning under change? J Water Resour Plan Manag 141:04015012

Howitt R, Medellín-Azuara J, MacEwan D, Lund J, Sumner D (2014) Economic analysis of the 2014 drought for California agriculture. Center for Watershed Sciences. Memo to California Department of Food and Agriculture

Howitt R, MacEwan D, Medellin, Azuara J, Lund J, Sumner DA (2015) Preliminary analysis: 2015 Drought Economic Impact Study

Kallianpur G, Karandikar RL (2012) Introduction to option pricing theory. Springer Science \& Business Media

Lempert R, Nakicenovic N, Sarewitz D, Schlesinger M (2004) Characterizing climate-change uncertainties for decision-makers. An editorial essay. Clim Chang 65:1-9

Linnenluecke MK, Griffiths A (2012) Assessing organizational resilience to climate and weather extremes: complexities and methodological pathways. Clim Chang 113:933-947

Messerli B, Viviroli D, Weingartner R (2004) Mountains of the world: vulnerable water towers for the 21st century. Ambio 29-34

Myers SC (1977) Determinants of corporate borrowing. J Financ Econ 5:147-175

Osgood DE, McLaurin M, Carriquiry M, Mishra A, Fiondella F, Hansen JW, Peterson N, Ward MN (2007) Designing weather insurance contracts for farmers in Malawi, Tanzania and Kenya: Final Report to the Commodity Risk Management Group, ARD, World Bank

Reservoirs (2016) List of largest reservoirs of California. Wikipedia

Somer L (2014) As water prices soar, some profit from California's drought. http://blogs.kqed. org/science/audio/some-california-farmers-fallow-fields-others-sell-water-for-big-profits/

Stephenson SR, Smith LC, Agnew JA (2011) Divergent long-term trajectories of human access to the Arctic. Nat Clim Chang 1:156-160

Tallis H, Kareiva P, Marvier M, Chang A (2008) An ecosystem services framework to support both practical conservation and economic development. Proc Natl Acad Sci 105:9457-9464

Tebaldi C, Knutti R (2007) The use of the multi-model ensemble in probabilistic climate projections. Phil Trans R Soc Lond A: Math Phys Eng Sci 365:2053-2075

Trigeorgis L (1993) Real options and interactions with financial flexibility. Financ Manag 202-224

Tucker M (1997) Climate change and the insurance industry: the cost of increased risk and the impetus for action. Ecol Econ 22:85-96

University of California, Davis, Available at http://drought.ucdavis.edu/

USGS (2014) Water-resources data for the United States, Water Year 2013: U.S. Geological Survey Water-Data Report WDR-US-2013, site 11266500. http://wdr.water.usgs.gov/wy2013/pdfs/11266500.2013.pdf

Wilby RL, Dessai S (2010) Robust adaptation to climate change. Weather 65:180-185 